\title{
Experimental Researchon Properties of High Strength Concrete (Hybrid)
}

\author{
R. Purusothaman, S. Vidhyalakshmi
}

\begin{abstract}
Hybrid Fibre ferroconcrete a composite may be termed as a hybrid two or additional kinds of fibres are combined during a common matrix provide composite that drives advantage from each of the individual fibres and Exhibits a synergetic response. Addition of short fibres plays a crucial role in the improvement of mechanical properties. It will increase elastic modulus decreases crispness controls cracks initiation and its resultant Growth and propagation. Deboning and pull out of the fibre need a lot of energy absorption, leading to a considerable increase within the toughness and fracture resistance of the materials to the cyclic and dynamic hundreds.
\end{abstract}

Index Terms-Joint probabilities, Machine translation, ngrams, Word Sense Disambiguation

\section{INTRODUCTION}

This experimental study is aimed to introduce steel fibre and nylon fibres. This project is carried out to increase the strength of RC \& study its durability. In our project, an experimental investigation was carried out to study the strength and durability behaviour of the proposed concrete mix. When steel fibres unit of measurement alternative to mortar, the flexural strength of the composite is increased from $25 \%$ - hundred percentage depending on the proportion of fibres other and also the combine style. Steel fibres are available in lengths from $38-50 \mathrm{~mm}$ and aspect ratios between $40 \& 60$

\section{MATERIALS}

A. Cement - Ordinary cement (OPC) is out and away from the foremost vital form of cement. The OPC was 3 grade namely 33grade, 43 grade, 53 grade depending upon the strength of the cement at 28 days when tested as per IS 8112-1989. Conforming weight of every cement bag was fifty kilograms.

\section{B. FINE AGGREGATE}

It should be passing through IS Sieve $4.75 \mathrm{~mm}$. Physical properties of aggregates determine per IS 2386-1968. It should have fineness modulus $2.50-3.50$ and silt content should not be more than $4 \%$.Grading limit of Fine aggregate confirming IS $383-1970$.

\section{C.COURSE AGGREGATE}

It ought to be laborious, strong, sturdy and clean.

It must be free from the vein, adherent coating, alkalis, and other deleterious substances. It should be conical. It should conform to IS 2386(part-1): 1963.

Revised Manuscript Received on April 12, 2019.

R. Purusothaman, $2^{\text {st }}$ yr. M.E, Structural Engineering (Civil),Saveetha School of Engineering, Chennai, T.N, India. (E-mail: Purusoth723@gmail.com)

Dr. S. Vidhyalakshmi, Associate Professor, Structural Engineering Saveetha School of Engineering, Chennai, T.N, India.

\section{WATER}

Locally available potable water should be free from acids, oils, alkalis, vegetables or other organic impurities.

\section{E. PROPERTIES OF STEEL FIBER}

Rule of thumb, tiny fibres tend to be used wherever management of crack propagation is that the most significant style thought. High fibre count permits finer distribution of SFR throughout the matrix - and consequently, larger crack management throughout drying method on the opposite hand, as a result of they exhibit higher matrix anchorage at high deformations and enormous crack widths, longer, heavily ill-shapen fibres afford higher post-crack "strength". Type - the diameter of fibre $0.12 \mathrm{~mm}$, length of fibre - $15 \mathrm{~mm}$, tensile strength $2300 \mathrm{mpa}$, density $-7.8 \mathrm{~g} / \mathrm{cc}$

\section{F. PROPERTIES OF NYLON FIBRES}

Nylon fibres, area unit many varieties counting on the raw materials. Structure - circular, density $-1.14 \mathrm{~g} / \mathrm{cc}$, crystallinity $-65-85 \%$.

\section{MIX PROPORTION (M40)}

\begin{tabular}{|c|c|c|c|}
\hline WATER & CEMENT & $\begin{array}{c}\text { FINE } \\
\text { AGGREGATE }\end{array}$ & $\begin{array}{c}\text { COARSE } \\
\text { AGGREGATE }\end{array}$ \\
\hline 185 & 380 & 793.35 & 806.25 \\
\hline .450 & 1.000 & 1.390 & 1.410 \\
\hline
\end{tabular}

\section{TEST\& RESULTS}

A. RESULTS OF SLUMP TEST

\begin{tabular}{|c|c|}
\hline MIX & SLUMP IN mm \\
\hline M40 (conventional) & 600 \\
\hline $1 \%$ & 550 \\
\hline $2 \%$ & 540 \\
\hline $3 \%$ & 500 \\
\hline $4 \%$ & 540 \\
\hline
\end{tabular}

\section{B.THE COMPRESSION STRENGTH}




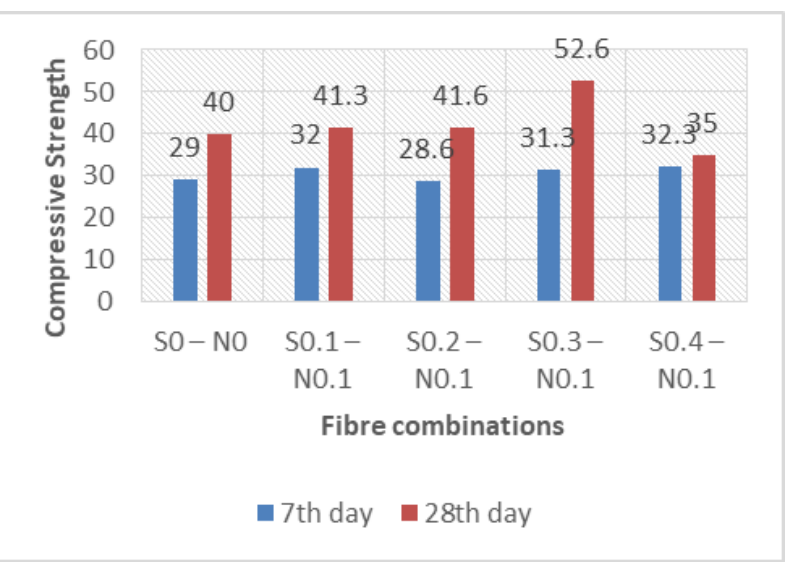

S0.4 - N0.1 (SF $0.4 \%$ and Nylon fibre $0.1 \%$ ) shows the highest value for 7 th day

$>$ S0.3 - N0.1 (SF $0.3 \%$ and Nylon fibre $0.1 \%$ ) shows the highest value for a 28 th day

\begin{tabular}{|c|c|c|}
\hline Sample & 7 Days & 28 days \\
\hline S0 - N0 & 29 & 40 \\
\hline S0.1-N0.1 & 32 & 41.3 \\
\hline S0.2- N0.1 & 28.6 & 41.6 \\
\hline S0.3- N0.1 & 31.3 & 52.6 \\
\hline S0.4- N0.1 & 32.3 & 35 \\
\hline
\end{tabular}

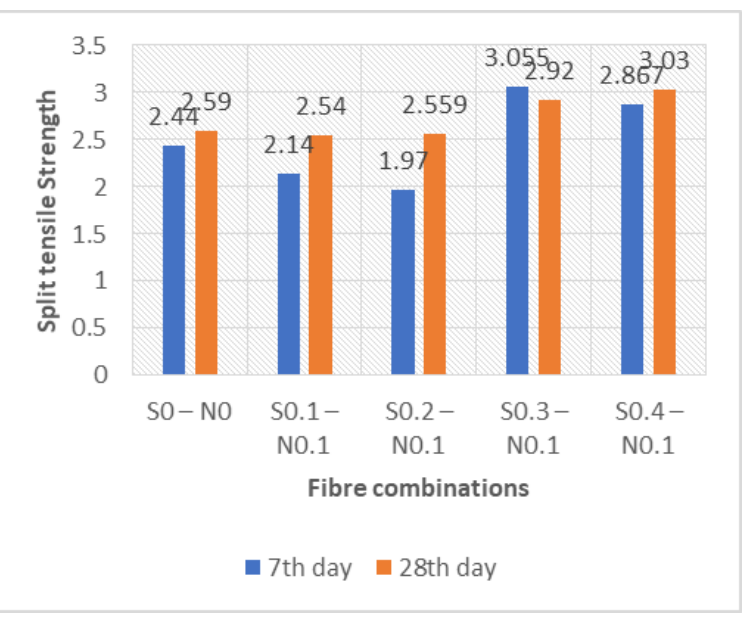

\section{C.SPLIT TENSILE TEST}

$>\mathrm{S} 0.3$ - N0.1 (SF $0.3 \%$ and Nylon fibre0.1\%) shows the highest value for 7 th day

$>$ S $0.3-\mathrm{N} 0.1$ (SF $0.3 \%$ and Nylon fibre $0.1 \%$ ) shows the highest value for a 28 th day

\begin{tabular}{|c|c|c|}
\hline Sample & 7 Days & 28 days \\
\hline S0 - N0 & 2.440 & 2.590 \\
\hline S0.1 - N0.1 & 2.140 & 2.540 \\
\hline S0.2- N0.1 & 1.970 & 2.559 \\
\hline S0.3 - N0.1 & 3.055 & 2.920 \\
\hline S0.4- N0.1 & 2.867 & 3.030 \\
\hline
\end{tabular}

D.FLEXURAL STRENGTH

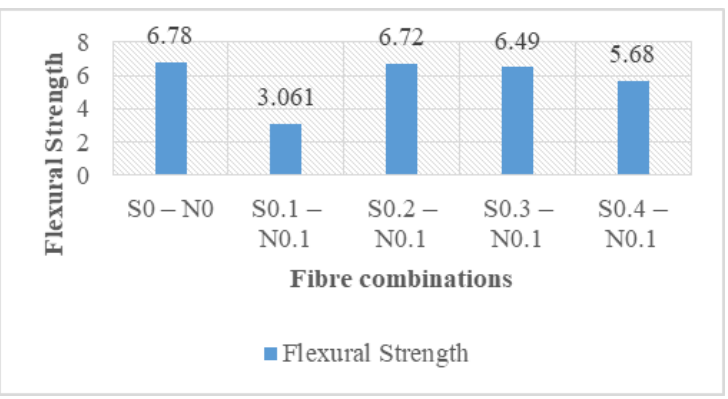

$>$ S0.3 - N0.1 (SF $0.3 \%$ and Nylon fibre $0.1 \%$ ) and S0.2 - N0.1 (SF $0.2 \%$ and Nylon fibre $0.1 \%$ ) shows similar results to that of conventional concrete.

\begin{tabular}{|c|c|c|}
\hline $\begin{array}{c}\text { Fibre } \\
\text { combination }\end{array}$ & $\begin{array}{c}\text { Average } \\
\text { (Load) }\end{array}$ & $\begin{array}{c}\text { Flexural Strength } \\
\left(\mathrm{N} / \mathrm{mm}^{2}\right)\end{array}$ \\
\hline S0 $-\mathrm{N} 0$ & 32.7 & 6.780 \\
\hline S0.1-N0.1 & 14.76 & 3.061 \\
\hline S0.2-N0.1 & 32.4 & 6.720 \\
\hline S0.3-N0.1 & 31.3 & 6.490 \\
\hline S0.4- N0.1 & 27.43 & 5.680 \\
\hline
\end{tabular}

\section{CONCLUSION}

$>$ The compressive strength results show that the use of $0.3 \%$ of Micro Steel fibres and $0.1 \%$ of Nylon fibres increases the compressive strength by about $31.5 \%$ on comparing it with Conventional concrete

$>$ The Split Tensile strength results show that the use of $0.3 \%$ of Micro Steel fibres and $0.1 \%$ of Nylon fibres increases the compressive strength by about $17.95 \%$ on comparing it with Conventional concrete

$>$ The Flexural strength results show that the use of $0.3 \%$ of Micro Steel fibres and $0.1 \%$ of Nylon fibres show similar results to that of Conventional concrete

Fibre combination of S0.3 - N0.1, SF0.3\% and Nylon Fibre $0.1 \%$ is recommended as it shows satisfactory results in Workability, Mechanical properties (Compressive, Split Tensile, and Flexure) Strength and Durability properties Strength on comparison with Conventional Concrete.

\section{REFERENCE}

1. Abul K. Azad, et al, 49 (2013) 128-133 8 August 2013

2. ArunMurugesan, et al, (2016), 29 October 2016

3. ErtekinOztekin, et al, (2002). high-performance concrete" Engineering Structures 25 (2003) 371-376, 8 October 2002

4. HalitCenan, et al, (2015)Building Materials 98 (2015) 185193, 24 August 2015

5. K. M. A. Hossain, et al,(2012) Self-Consolidating Concrete "American Society of Civil Engineers. 15 Sep 2012

6. M. A. Mansur, et al, (1998) cement and concrete composites ( 1998), 477 - 486, 20 September 1998

7. M. Paja $\mathrm{k}$, et al, (2013) Construction and Building Materials 47 (2013) 397-408. 29 August 2013.

8. M.N. Soutsos, et al, ( 2011) Construction and Building Materials 98 (2011) 185-193, 21 August 2011

9. TogayOzbakkaloglu, et al, (2004) ACI Structural Journal, V. 101, No. 4, July-August 2004.

10. S.S. Vivek, et al, (2017) Construction and Building Materials 152 (2017) 57-64, 24 May 2017. 